Barrison IG, Viola L, Murray-Lyon IM. Do housemen take an adequate drinking history? Br Med $\mathcal{F}$ 1980;281:1040.

2 Rowland N, Maynard A, Beverage A, Kennedy P, Winfergill W, Stone W. Doctors have no time for alcohol screening. Br Med f 1987;295:95-6.

Paton A. Alcohol misuse and the hospital doctor. Br f Hosp Med 1989;424:394-8.

4 Ford M, Ritson B. Medical students attitudes towards alcohol problems. Proceedings of the Royal College of Physicians of Edinburgh 1990 (in press).

Glass IB. Undergraduate training in substance abuse in the United Kingdom. Br f Addict 1989;84:197-202.

6 Macdonald EB, Patel AR. Attitudes towards alcoholism. Br Med f 1975; ii:430-1.

7 Mendelson JH, Wexler D, Kubjorsky PE, Harrison R, Leiderrman G, Solomon P. Physicians attitudes toward alcoholic patients. Arch Gen Psychiatry 1964;11:392-9.

8 Office of the Chief Scientist. Alcohol related problems in undergraduate medical education. London: DHSS, 1987

9 Ariff A, Westermeyer J. Manual of drug and alcohol abuse. Guidelines for teaching in medical and health institutions. New York: Plenum Press, 1988.

\section{Who should take vitamin supplements?}

\section{Healthy people eating a healthy diet do not need them}

In 1988 a multivitamin and multimineral supplement was reported to improve the performance in non-verbal intelligence tests of 30 schoolchildren in Wrexham in an eight month double blind trial. Though the authors warned that their study needed to be repeated, for the media it was big news. The story broke on television two days before the article was published in the Lancet. ${ }^{1}$ The British nutrition establishment found many weaknesses in the trial,,$^{2-9}$ and two attempts to confirm the results failed. ${ }^{1011}$ Yet the public continues to believe in vitamins: one such persistent belief is that vitamin $\mathrm{C}$ will prevent colds, despite a meta-analysis of 27 controlled trials having shown that vitamin $\mathrm{C}$ has no worthwhile effect. ${ }^{12}$ So is any benefit to be expected for ordinary people from vitamin supplements?

Expert committees do not think so-at least for the populations of affluent countries. The American Institute of Nutrition and Society for Clinical Nutrition recommends that "healthy children and adults should obtain adequate nutrient intakes from dietary sources. Meeting nutrient needs by choosing a variety of foods in moderation, rather than by supplementation, reduces the potential risk for both nutrient deficiencies and nutrient excesses. Individual recommendations regarding supplements and diets should come from physicians and registered dietitians."13 The United States National Research Council could find "no documented reports that daily multiple vitamin-mineral supplements, equalling no more than the recommended dietary allowances . . . are either beneficial or harmful for the general population." ${ }_{14}$ Dismissive recommendations like this are incomplete unless they give guidance on the outlines of an adequate diet - for example, "people eating a good diet that includes bread and cereals, vegetables and fruit, meat or meat substitutes and dairy products do not require vitamin and mineral supplements." 15 The consensus is clear: "healthy adult men and healthy non-pregnant, non-lactating women consuming a normal varied diet do not need vitamin supplements." 16

Three things may go wrong when people choose to treat themselves with vitamin preparations. Firstly, people eating a good diet are more likely to take supplements regularly than those at risk of nutrient deficiency. ${ }^{17} 18$ Secondly, the vitamins people choose to take are often not the ones inadequate in their diet. ${ }^{19}$ Thirdly, the preparations available do not make it clear whether the doses of vitamin they contain are near the nutrient requirement or many times greater. Toxic effects are now well established for megadoses of water soluble pyridoxine (vitamin B-6), ${ }^{20}$ as well as for fat soluble vitamins $A$ and $D$. In summary, all too often the wrong people are taking the wrong doses of the wrong vitamins. ${ }^{21}$

On the other hand, when well fed people take vitamins in nutritional doses and not megadoses they can do no harm. The medical interest in vitamins should perhaps concentrate on the indications for supplements in groups of people at risk of deficiency. Newborn infants need vitamin $\mathrm{K}$. In pregnancy the most critical nutrients are folic acid, iron, and calcium. The same three nutrients may be needed in lactation, and the suckling infant's intake from breast milk of most vitamins can be increased if the mother takes supplements. Vitamin D may be needed in winter by children in the north of Britain and by anyone who is housebound. Vegans, and especially their infants, require vitamin B-12 supplements. Alcoholics should receive supplements of thiamine. Then for various conditions a multivitamin supplement may be indicated: people with low calorie intake, those taking weight reducing diets or with poor appetites, and the elderly and frail, food faddists, the emotionally disturbed, and socially disadvantaged people.

It is, however, difficult to find a good multivitamin. The ideal preparation would provide the recommended daily amount $^{22}$ or recommended dietary allowance ${ }^{23}$ of all 13 vitamins ${ }^{24}$ and none of the non-vitamins, as in the Australian product Elevit. There is no such preparation in the British National Formulary. Those listed contain mostly from four to seven vitamins, never more than 10 , and rarely include folic acid. The doses and their ratios vary inexplicably. Thiamine, for example (requirement $1.0 \mathrm{mg}$ per day) ranges from 0.5 to $5.0 \mathrm{mg}$ per tablet or capsule.

Lastly, some hypotheses are now being tested for prophylactic use of vitamins beyond preventing clinical or subclinical malnutrition. A definitive answer is awaited from the trial studying the use of vitamins at the start of pregnancy to reduce the risk of neural tube defect in babies born to women who have previously had an affected baby. ${ }^{25} 26$ Another general hypothesis with wide implications is that one of the "antioxidant" vitamins, vitamin A, $\beta$ carotene (or even a nonprovitamin A carotenoid), vitamin C, or vitamin $\mathrm{E}$ may confer some protection against the development of some types of cancer. ${ }^{27}$ None of the present evidence is more than suggestive. Prevention trials have started and we may expect others to be set up.

Boden Professor of Human Nutrition,

STEWART TRUSWELL

University of Sydney,

New South Wales 2006,

Australia

1 Benton D, Roberts G. Effect of vitamin and mineral supplementation on intelligence of a sample of schoolchildren. Lancet $1988 ;$ i: 140-3.

Emery PW, Nelson M, Saunders TAB, et al. Vitamin/mineral supplementation and non-verbal intelligence. Lancet $1988 ;$; 407 .

3 Hutton JL, Ashby D. Vitamin/mineral supplementation and non-verbal intelligence. Lance $1988 ; i: 407$.

4 Yudkin J. Vitamin/mineral supplementation and non-verbal intelligence. Lancet 1988;i:407.

5 Bates CJ, Thurnham DI, Powers HJ. Vitamin/mineral supplementation and non-verbal intelligence. Lancet 1988;i:407.

6 Macnair A. Vitamin/mineral supplementation and non-verbal intelligence. Lancet 1988;i:407-8. MacFarlane A. Vitamin/mineral supplementation and non-verbal intelligence. Lancet 1988;i:408.

8 Rose GA. Vitamin/mineral supplementation and non-verbal intelligence. Lancet 1988;i:408.

9 Bender AE. Vitamin/mineral supplementation and non-verbal intelligence. Lancet 1988;i:409.

10 Naismith DJ, Nelson M, Burley VJ, Gatenby SJ. Can children's intelligence be increased by vitamin supplements? Lancet 1988 ;ii:335.

11 Crombie IK, Todman J, McNeill G, Florey C du V, Menzies I, Kennedy RA. Effect of vitamin and mineral supplementation on verbal and non-verbal reasoning of school children. Lancet 1990;335: 744-7.

12 Truswell AS. Ascorbic acid and colds. N Engl f Med 1986;315:709.

13 Joint Public Information Committee of the American Institute of Nutrition and the American Society for Clinical Nutrition. Statement on vitamin and mineral supplements. $\mathcal{F}$ Nutr 1987;117:1649.

14 Committee on Diet and Health, Food and Nutrition Board National Research Council. Diet and health. Implications for reducing chronic disease risk. Washington, DC: National Academy Press,

15 Department of Community Services and Health; National Health and Medical Research Council. Nutrition policy statements. Canberra:ACT, 1988:53.

16 American Medical Association Council on Scientific Affairs. Vitamin preparations as dietary supplements and as therapeutic agents. fAMA 1987;257:1929-36.

17 Surgeon General. Surgeon General's report on nutrition and health. Washington DC: United States Department of Health and Human Services, 1988:71. (Publication PHS 88-50210.) 
18 Worsley A, Crawford D. Australian dietary supplementation practices: an overview of two recent surveys. Food Technology in Australia 1984;36:547-51.

19 Allen JA, Roberts DCK, O'Connell D, et al. Vitamin and mineral supplement use in an Australian adult group. Proceedings of the Nutrition Society of Australia 1987;12:163.

20 Parry GJ, Bredesen DE. Sensory neuropathy with low-dose pyridoxine. Neurology 1985;35: 1466-8. 21 Truswell AS. The vitamin debate today. Australian Pharmacist 1985;4:21-3,32.

21 Truswell AS. The vitamin debate today. Australian Pharmacist 1985;4:21-3,32. for groups of people in the United Kingdom. Report by the Committee on Medical Aspects of Food for groups of people in the United Kingdom. Report by the Committee on M
Policy. London: HMSO, 1981. (Report on Health and Social Subjects 15.)

23 Food and Nutrition Board, National Academy of Sciences-National Research Council. Recommended dietary allowances. 10th ed. Washington, DC: National Academy of Sciences, 1989 24 Truswell AS. Vitamins. In: $A B C$ of nutrition. London: British Medical Journal, 1986:57-63. 25 Harris R. Vitamins and neural tube defects. Br Med $\mathcal{F}$ 1988;296:80-1.

26 Mulinsky A, Jick H, Bruell CL, et al. Multivitamin/folic acid supplementation in early pregnanc reduces the prevalence of neural tube defects. FAMA 1989;262:2847-52.

27 Moon TE, Micozzi MS, eds. Nutrition and cancer prevention. Investigating the role of micronutrients. New York: Marcel Dekker, 1989

\section{Prognosis of abdominal aortic aneurysm}

\section{Operate on tender aneurysms, but get better data on small asymptomatic aneurysms}

Abdominal aortic aneurysm is common, and studies in Britain, North America, and Australia show a rising prevalence. ${ }^{1-3}$ In Britain rupture or complications of abdominal aortic aneurysms kill 10000 people each year ${ }^{4}$; a further 2000 3000 undergo successful aortic grafting, but many more die with their aneurysms intact. Necropsy studies suggest that aneurysms are present in 3\% of those aged over 50.5 Abdominal aortic aneurysm is therefore potentially lethal but not always the killer. Recent screening studies suggest that asymptomatic small aneurysms are frequent among people aged $65-74 .^{6-8}$ The prognosis - and hence the ideal management-of these asymptomatic aneurysms, however, is not clear.

Elective replacement of an aortic aneurysm with a Dacron graft is a safe, standard, and durable procedure; Dacron is inert and outlives the patient provided that no infection occurs at bypass. A review of our data on 325 consecutive aneurysm repairs done over a decade, looking at 30 day as well as 24 hour mortality, showed a considerable difference in mortality according to whether the aneurysm was symptomatic. For 134 patients with asymptomatic aneurysms the 24 hour mortality was zero and 30 day mortality $1.4 \%$; for 120 patients with an inflammatory aneurysm or a tender aneurysm suggesting impending rupture the 24 hour mortality remained low $(0.8 \%)$ but 30 day mortality rose to $9.2 \%$; for 71 patients with ruptured aneurysms the 24 hour mortality was $19 \cdot 7 \%$ and 30 day mortality $42 \cdot 2 \%$. Others have reported similar experiences..$^{9-11}$

Thus for patients with asymptomatic aneurysms mortality during the first 30 days after surgery is little more than that expected over long term follow up-that is, $9 \%$ a year. But despite the increase in elective repairs the number of patients admitted with ruptured aneurysms continues to rise. ${ }^{\prime}$ The contrasting mortality figures for ruptured and unruptured aneurysms suggest that tender aneurysms should be operated on urgently, before they rupture. The difficulty remains with asymptomatic aneurysms.

The risk of rupture of an asymptomatic aneurysm probably increases with the maximum diameter, ${ }^{12}$ but age and general health are also important. Aneurysms are a disorder of the seventh and eighth decades, and death from other causes may precede rupture. Most British surgeons favour surgery for asymptomatic aneurysms over $5.5 \mathrm{~cm}$ in diameter, but the management of smaller aneurysms is controversial. All favour observation of aortic swellings of up to $4 \mathrm{~cm}$, and some operate on aneurysms of that size, ${ }^{13}$ even though the size of a small aorta is uncertain (unpublished data). Nevertheless, preliminary data indicate that asymptomatic aneurysms of less than $5 \mathrm{~cm}$ do not benefit from elective repair. ${ }^{15} \mathrm{~A}$ recent retrospective review of 176 patients with abdominal aortic aneurysm in Rochester, Minnesota, showed that aneurysms of $5 \mathrm{~cm}$ or less were unlikely to rupture. ${ }^{16}$

Information on factors associated with aortic dilatation comes only from retrospective studies of patients unfit for elective surgery. ${ }^{17-19}$ These factors include the absence of peripheral arterial disease; a small ratio of suprarenal aortic diameter to infrarenal diameter; hypertension; and obstructive lung disease. The rate of growth of small aneurysms seems to vary widely, from $2 \mathrm{~mm}$ to $8 \mathrm{~mm}$ a year. ${ }^{17-20}$ One retrospective analysis suggested that $\beta$ blockers diminished the rate of growth from about $5 \mathrm{~mm}$ a year to less than $2 \mathrm{~mm} .^{21}$ Such studies simply compound the dilemma of whether to operate on small asymptomatic aneurysms and add nothing to knowledge or understanding of the natural course.

Clearly, once an aneurysm of any size has become tender it is lethal and should be operated on. Although operative mortality is low for asymptomatic aneurysms, we have inadequate prospective data on the growth of small aneurysms, their rates of rupture, and mortality from rupture or other causes during observation, and we know next to nothing about the factors affecting dilatation. We need national 30 day mortality figures for elective repairs according to age, sex, and size of aneurysm, not just reports from specialist centres. A national collaborative trial of the management of patients with asymptomatic abdominal aortic aneurysms could provide this information. Only then could we comment on the prognosis of small asymptomatic aneurysms and whether observation or operation is better.

R M GREENHALGH

Professor of Surgery,

Charing Cross and Westminster Medical School,

London W6 8RF

Fowkes FGR, Macintyre GAA, Ruckley CV. Increasing incidence of aortic aneurysms in England and Wales. Br Med F 1989;298:33-5.

Melton LJ, Bickerstaff LK, Hollier LH, et al. Changing incidence of abdominal aneurysms-a population based study. Am $\mathcal{F}$ Epidemiol 1984;120:379-86.

Castleden WM, Mercer JC. Abdominal aortic aneurysms in Western Australia; descriptive epidemiology and patterns of rupture. Br F Surg 1985;72:109-12.

Office of Population Censuses and Surveys. Mortality statistics. London: HMSO, 1984.

5 Turk KAD. The postmortem incidence of abdominal aortic aneurysm. Proceedings of the Royal Sociely of Medicine 1965;58:869-70.

6 Scot RAP, Ashton HA, Kay DN. Routine ultrasound screening in the management of abdominal artic aneurysms. Br Med f 1988;296:1709-10.

7 Collin J, Araujo L, Walton J, Lindsell D. Oxford screening programme for abdominal aortic aneurysms in men aged 65-74 years. Lancet 1988;ii:613-5.

8 Allardice JT, Allwright GJ, Wafula JMC, Wyatt AP. High prevalence of abdominal aortic aneurysm in men with peripheral vascular disease: screening by ultrasonography. $\mathrm{Br} \mathcal{F}$ Surg $1988 ; 75: 240-2$

9 Fielding JWL, Black J, Ashton F, Slaney G. Ruptured aortic aneurysms: postoperative complications and their aetiology. Brf Surg 1984;71:487-91

10 Hicks GL, Eastland MW, DeWeese JA, et al. Survival improvement following aortic aneurysm surgery. Ann Surg 1975;181:863-9.

1 Jenkins A, Ruckley CV, Nolan B. Ruptured abdominal aortic aneurysm. Br f Surg 1986;73:395-8. 12 Darling RC. Ruptured arteriosclerotic abdominal aortic aneurysms. Am f Surg 1970;119:397.

13 Collin J. Elective surgery for small abdominal aortic aneurysms. Lancet 1987;i:909.

15 Johansson G, Nydahl S, Olofsson P, Swedenborg J. Survival in patients with abdominal aoric aneurysms. European fournal of Vascular Surgery (in press).

aneurysms. European fournal of Vascular Surgery (in press).
6 Nevitt MP, Ballard DJ, Hallett JW Jr. Prognosis of abdominal aortic aneurysms. A population revitt MP, Ballard DJ, Hallett JW Jr. Prognosis

17 Cronenwett JL, Murphy TF, Zelenock GB, et al. Actuarial analysis of variables associated with rupture of small abdominal aortic aneurysms. Surgery 1985;98:472-82.

18 Sterpetti AVC, Schultz RD, Feldhaus RJ, et al. Factors influencing enlargement rate of small bdominal aortic aneurysms. F Surg Res 1987;43:211-9.

19 Littooy FN, Steffan G, Greisler HP, White TL, Baker WH. Use of sequential B-mode ultrasonography to manage abdominal aortic aneurysms. Arch Surg 1989;124:419-21.

20 Collin J, Araujo L, Walton J. How fast do very small abdominal aortic aneurysms grow? European Journal of Vascular Surgery 1989;3:15-7.

21 Leach SD, Toole AL, Stern H, DeNatale RW, Tilson MD. Effect of beta-adrenergic blockade on the growth rate of abdominal aortic aneurysms. Arch Surg 1988;123:606-9. 